\title{
Psycholinguistics Approach to Study of Female Stereotypes in the Armed Forces of Ukraine
}

\author{
Tetyana Khraban, Oleksiy Silko
}

Heroiv Krut Military Institute of Telecommunications and Information Technologies, Kiev, Ukraine

\author{
Email address: \\ Xraban.Tatyana@gmail.com (T. Khraban),silko@viti.edu.ua (O. Silko)
}

\section{To cite this article:}

Tetyana Khraban, Oleksiy Silko. Psycholinguistics Approach to Study of Female Stereotypes in the Armed Forces of Ukraine. American Journal of Applied Psychology. Vol. 10, No. 2, 2021, pp. 40-48. doi: 10.11648/j.ajap.20211002.12

Received: April 6, 2021; Accepted: April 16, 2021; Published: April 26, 2021

\begin{abstract}
This article is aimed to substantiate and explain the outcome of the empirical, inductive study of the website of a Ukrainian "Military Service" group. The language level of female stereotypes in the Armed Forces of Ukraine was subjected to analysis through studying of the gender stereotype functions conditionally divided into psychological and social ones. As a main research method was used discourse analysis. Cognitive-adaptive function is realized through the cognitive gender metaphor, which are becoming tools that breaks down traditional female stereotypes and offer a new perspective, namely the failure of polarization between the genders. The value-protective function of female stereotypes is aimed to maintain collective values, justify and rationalize discriminatory attitudes towards the outgroups. Constructive function of gender stereotyping favors the emancipation of a serviceman, helps to prevent the stress associated with the need to obey in armed forces, lets adopt the form and manner of behavior in typical social situations that presuppose strict military discipline, subordination and unity of command, lets a serviceman perceive and evaluate a woman based on the characteristics of her inner world and her professional activities. Emotional-evaluative function of female stereotypes helps military man in the Armed Forces of Ukraine reproduce situations that are emotionally significant for him, in which his needs in recognition and love have been met. Further, this can contribute to creation of psychological comfort and deep emotional ties between men and women in a military collective.
\end{abstract}

Keywords: Gender Stereotype, Discourse Analysis, Female Stereotypes, Armed Forces, Psycholinguistics

\section{Introduction}

The gender policy in the Armed Forces takes tangible measures to ensure the full implementation of the career or professional ambitions of Ukrainian women in the military [21], to correct the imbalance of women's representation in Armed Forces of Ukraine, to organize the military service in such way, which "takes into account gender differences and at the same time takes into account the argument of justice (equal rights and opportunities for every person regardless of gender) as well as the argument of efficiency (involvement of the social and professional potential of women)" [25]. The total number of women in the Armed Forces of Ukraine is growing (women represent 15 per cent of the military, 902 women have senior officer ranks as of March 2020; two women in Ukraine achieved the rank of major general as of August 2020) [28]. Women are enrolled on equal terms with men in the military higher educational institutions where they can acquire specialties, according to which they can serve in the army as officers. Thus, Gender Policy in the Armed Forces of Ukraine is aimed at affirmative action, that is, the implementation of a large number of measures taken legally to support and encourage women who have been previously in a disadvantaged position as members of society in order to open career opportunities in the military service by putting men and women on an equal competition basis [33]. In this regard, studying of gender stereotyping and gender role formation in the Armed Forces of Ukraine can contribute to the development of desirable options of female representation in armed services.

\section{Literature Review}

Sociological studies dealing with the problem of gender equality in Ukrainian society and in the Armed Forces of Ukraine, women's participation in armed conflicts have made a significant contribution to the study of trends in gender processes that are currently taking place in the 
Ukrainian army. Summarizing the results of the sociological research Martsenyuk, Hrytsenko, Kvit, Berlinskaya [26] note that women in the Armed Forces of Ukraine experience gender discrimination and bias from their superiors. Men perceive war as a man's job, while women are considered unworthy to take part in it and they are believed can only serve man's needs. The main reasons for gender discrimination are identified as outdated traditions and ideas about the role and place of women in society, the inadequacies of the legislative framework relating to the protection of human and civil rights (regardless of gender), the lack of effective mechanisms for introducing the ideas of gender equality, the discrepancy of gender standards of the Armed Forces of Ukraine with the social needs of the military. On the other hand, women themselves do not always believe in their power to enter more traditionally "male" professions. A number of researchers (Vikhor, Toporenko [36], Slipushko [32], Kalagin [19] and others) indicate that selfrealization of women in the Armed Forces of Ukraine occurs in the conditions of tough struggle between public opinion and the patriarchal worldview. The integration of women into the Armed Forces of Ukraine does not receive adequate support in Ukrainian society through the existing of gender stereotypes and legislative discriminatory practices, the personal hostility of soldiers, noncommissioned and commissioned officers of the Armed Forces of Ukraine to the female presence in the army, inadequate media coverage etc. [36]. Dubchak [14] reached interesting conclusions regarding female stereotypes in the Armed Forces of Ukraine. The researcher sees the reasons of the obstacles encountered during the integration of women into the Armed Forces of Ukraine not in the detrimental force of stereotypes, but in the peculiarities of female psychology: "women are not always ready to recognize and obey the leader and the best one among themselves, because they see every other woman as a competitor" [14].

The studies of Kirk [22], Miller, Moskos [27], DeGroot [11], Boldry, Wood, Kashy [6], in which issues regarding the men's attitude to the possibility of women to be professional military are raised, contribute to a deeper and more unbiased understanding of the gender stereotyping and gender role formation. Thus, Boldry, Wood, Kashy [6] investigated perceptions of men and women in the Texas A\&M Corps of Cadets. The researchers concluded that the cadets believe men more than women possess the motivation and leadership qualities necessary for effective military performance, whereas women possess more feminine attributes that impair effective military performance. Nevertheless, the researchers noted the successful integration of women into the strongly male-dominated setting owing to more favorable stereotypic judgments of women. Review of debates focused on the feasibility of integration women into the armed services shows that the arguments of opponents of gender equality are concerned mainly women's physical and psychological inability for military service. Collins-Dogrul and Ulrich [10] examined reader responses to editorials opinion about women in combat. They concluded that the rationale for denying the feasibility of integration women into armed services is based on a logic of averages, which in everyday life usually reflects the recourse to traditional stereotypes. Opponents of integration women into armed services categorize women as inferior soldiers and argue that desegregation puts individual soldiers and the nation at risk. Conversely, supporters of integration suggest that granting to women the right to serve in ground combat will advance both equality and military readiness. Collins-Dogrul and Ulrich [10] argue that public comments about women's participation in hostilities provide an opportunity to explore gender stereotypes in society. Results of research carried out by Doan and Portillo [12] demonstrate that gender stereotypes often work against changes, especially when these changes have the potential to disrupt an organization's culture and standard operating procedures of a military organization.

From the perspective of the effects of gender stereotypes on combat performance it should be mention the study conducted by Archer [5]. The author argues that female stereotypes in the US Marine Corps (USMC) have the potential to undermine a female Marine's performance, and sometimes the performance of others around her. So, disputes over the full parity of men and women in the armed services underline the topicality to study gender stereotypes in the military [8, 30].

This article is aimed to substantiate and explain the outcome of the empirical, inductive study of the website of a Ukrainian "Military Service" group. The language level of the reproduction and changing of female stereotypes in the Armed Forces of Ukraine was subjected to analysis through studying of modern Ukrainian military non-institutional discourse.

\section{Research Methods}

\subsection{A Discursive Approach for Research Studies on Gender Stereotypes}

Central to study the reproduction and changing of female stereotypes in the Armed Forces of Ukraine is the thesis of social and communicative nature of a person. The shift of psychology and social sciences to a fundamentally new socio-psychological ontology requires new theoretical and methodological, mainly interdisciplinary and integrative, approaches. The focus on achieving the most efficient results in studying of modern Ukrainian military non-institutional discourse requires consideration of discourse analysis as the main methodological approach. In this study, discourse is understood as "the external speech phase of professional speech production that is associated with the explication of internal intentions; the unity of linguistic and extra-linguistic aspects of the external phase of speech production, which determines its final result, that of an utterance, that provides expedient speech interaction" [20]. The starting point of discourse analysis is the statement that we gain access to 
reality through a language that not only reflects reality, but also constructs it. In other words, language is not just a channel for information exchange about phenomena, facts or behavior of people, but a mechanism that generates and constitutes the social world [17]. The discursive approach for research studies on gender stereotypes in the Armed Forces of Ukraine is consistent with an emerging trend in practice and doctrine that draw a researcher's attention to a real person and life situations. It is important that, insofar as military non-institutional discourse is an interdisciplinary object of research, involving of both related disciplines and various branches of psychology becomes more and more frequent. This creates conditions for an extensive and diverse application of the data received and, no less important, takes up new research topics that have been hidden by the so-called "boundaries" between different branches of knowledge [31]. When viewed from the perspective of psycholinguistics and sociolinguistics, the sphere of research interests of gender stereotypes in the Armed Forces of Ukraine becomes the external phase of speech production, which affects the grammatical structuring and choice of the word form (the level of the lexical and grammatical structure of the sentence), and the internal phase of the speech-thinking process, in which the explication of intentions is realized, notably the embodiment of the internal (semantic) program of utterance (semantic syntax) and the verbalization of the meanings selected in the internal speech [3].

\subsection{Procedure}

At the first stage, the reproduction and changing of female stereotypes in the Armed Forces of Ukraine were studied basing on qualitative content analysis to focus on understanding gender as a structuring element of corporate interaction; the analysis of the relationship between sociopsychological phenomena and the reproduction and changing of gender stereotypes has been carried out. In doing so, qualitative content analysis involved the systematic fixation of certain elements of the text content to set up the typologies of the data received and it was aimed to study the full range of phenomena by means of a case study. At the second stage, interpretive and explanatory methods of discourse analysis were used.

\subsection{Research Material}

The material for our empirical research are text fragments and photographs that are posted on the website of "Military service" Ukrainian group. This group has been created with the aim of uniting Ukrainian military personnel and giving them the opportunity to participate in discussions on issues that are relevant in the Armed Forces of Ukraine. Based on the fact that the policy of the group's administrators is aimed to limit access for persons who haven't served in the Armed Forces of Ukraine, it can be argued with a high degree of certainty that the publications on the website of "Military service" group have been posted by the military.

\section{Results and Discussions}

\subsection{A Theoretical Approach to Understanding the Term "Gender Stereotype"}

In the study gender stereotypes are understood as "a culturally and cognitively conditioned and generalized perception of a stable character concerning the attributes, roles and responsibilities of men and women" [2]. The semantics of the gender stereotype content becomes an internal mechanism of the individual's representation of the entire system of social relations, which are regarded as a form of mass consciousness, through which the intergroup interactions in society are established [18]. According to the social role theory the root cause of gender stereotypes is the discrepancy in the division of activities between men and women both at home and at work. The contrasting gender distribution of activity suggests that there are differences between men and women; and this idea begets gender stereotypes [23]. Gender stereotypes are rooted in mythology, religion, philosophy, so the concepts of masculinity and femininity differ depending on their belonging to a particular culture. Mention must be made, in that context, of the linkages that have historically developed in Ukraine between gender and the army as a social institution. Around the world war historically has been, and continues to be considered a male domain. In Ukraine Zaporizhian Sich was instrumental in gender stereotyping and gender role formation in the army. Zaporizhian Sich was the Cossack's administrative center, which lasted from the middle of the 16th century until 1775 . The preconditions for its formation were primarily the Cossacks' need for self-organization caused by the growth of army, and the need to protect Ukrainian lands from Tatar aggression [37]. Conclusions about the status of women are mainly based on the study of Cossack asceticism, that is resignation of their families, women, children and the devotion only to military service. Women were prohibited from entering the territory of Zaporizhian Sich, they were delegitimized here. Zaporizhian Sich was a military organization and the presence of women in the military was considered to be a destabilizing factor. Although there was a ban on women on territory of Zaporizhian Sich, in the conditions of life characterized by the precarious situation near the Tatar borders, a woman often had to defend her family home and her household. Life at the border taught women endurance, independence, courage, the ability to stand up for themselves and their families with weapons in their hands $[4,9,24,37]$.

The modern concepts of gender equality and gender egalitarianism have triggered the process of integrating women into the military. In Ukraine this process "can have two different scenarios: either women will adapt to preexisting in the military norms and orders, which are traditionally masculine in nature, or by their presence women will change the structure and nature of the army and make it as gender-neutral as possible" [26]. Reflecting on possible 
ways of integrating women into the Armed Forces of Ukraine, we consider it necessary to study those aspects which directly affect the process of communication and interaction between two gender groups. This process is mediated by many factors: the positions of the participants in the interaction, role expectations, the nature of the situation and the type of interaction, whether it be cooperation or competition [18]. All of them are reflected in social, including gender, stereotypes. Therefore, when analyzing intergroup interaction there is a clear need for gender stereotype analysis. In this research work the process of the reproduction and changing of gender stereotypes in the Armed Forces of Ukraine are studied through the gender stereotype functions that can be conditionally divided into psychological and social ones. The psychological functions of gender stereotypes serve for the effective comprehension and successful interpretation of an unusual, unexplored events or unknown persons by attributing to them typical characteristics of familiar objects. The social functions of gender stereotypes are aimed to maintain social order. They are conditioned by the ability of stereotypes to act as a factor of social relations. This is, firstly, the function of maintaining social control, namely the system of processes and mechanisms to ensure socially acceptable patterns of behavior and effective functioning of the social system as a whole [18]. In the first phase of this study the influence of the female stereotypes on the perception of female military personnel by male military personnel was analyzed.

\subsection{Cognitive Gender Metaphor as a Tool of the Cognitive-Adaptive Function of Stereotyping}

First of all, it should be mentioned that military personnel often deal with a situation of uncertainty, instability and increased danger as part of their work. In order to understand the situation and decide how to handle it, serviceman turns to stereotyping. Meanwhile, the cognitive-adaptive function becomes active and aims at simplifying and systematizing the knowledge received by the individual from the environment, thereby serves to save the individual's efforts in the perception of complex phenomena. The consistent and clear appreciation of the situation can be got through a cognitive gender metaphor. The gender metaphor appears when concepts of masculinity and femininity as basic ontological categories are applied to objects that are not related to gender $[7,16]$. On the one hand, cognitive gender metaphors are "a peculiar way of creating stereotypical structures of beliefs, as they can implicitly offer people a frame to interpret the social world from a specific perspective. However, on the other, metaphors might also be a tool to challenge tacitly shared stereotypical knowledge by offering a new perspective which reveals previous strategies of framing" [15]. Let us consider the feminine metaphorical representation of the $12.7 \mathrm{~mm}$ DShK heavy machinegun, namely "Dashka" (Dashka is a Ukrainian feminine given name, often a nickname for Daria): This description is dedicated to all whose name is Dashka and their boyfriends. Guys, hold on. Trust me, I know the feeling... The main problems with Dashka are their exboyfriends. They all know better than you and advise you how to caress your Dashka. Moreover, everyone says that his method is correct, and that he did everything right. And Dashka is capricious. If you have done something wrong, everything is finished. She glares at you with a jammed cartridge, a skewed cartridge case and a muzzle torn to pieces. You lend a listening ear to the advice of experienced Dashka's boyfriends, but she occurs to jam. Why? Because it's Dashka, that's why... The final problem with Dashka is that when you are together, everyone wants to kill you... And when they see you with such a queen, they immediately start shelling you with anti-tank guided missiles [38]. In this example the entirety of spiritual, intellectual and emotional properties united by the semantic component 'femininity' is attributed to an inanimate object. In this case, the feminine metaphor uses the whole range of associations with woman to actualize the socio-psychological characteristics of woman [29]: sensitivity, rapid change in emotional states, susceptibility, emotionality, vulnerability, hysteria, capriciousness. Thus, in the feminine metaphor structure we identify traditional female stereotypes as non-reflective images that nevertheless exist and form the cognitive model of woman in the minds of military men. However, the presence in the text of verbal signs of integration (lexical category of fraternity, words with the connotation 'we', evaluative words) demonstrates not only the absence of polarization, but also the trust and support between man and woman in a military corporate culture.

\subsection{The Value-protective Function of Stereotyping}

The purpose of value-protective function of gender stereotypes is not only to explain and protect group attitudes and behavior but also to sustain collective values, to justify and rationalize discriminatory attitudes towards an outgroup [13]. Consider the following example presented as a comparison table for better understanding:

Table 1. Humorous Comparison between Glamour Girl and T-64 tank.

\begin{tabular}{ll}
\hline Glamour Girl & T-64 tank \\
She costs you a lot of money & The state pays extra for its use \\
She bats her eyes at you & It has $125 \mathrm{~mm}$ smoothbore gun, 12.7 and 7.62 mm machine guns \\
She spends a lot of time in the bathroom & It is not afraid of mud \\
She wears impractical shoes & It's predicted range is $600 \mathrm{~km}$ \\
She fears everything & It terrifies the enemy \\
She moans on and on & It roars with a boxer engine \\
She is warm and soft & It has armor equivalent to $900 \mathrm{~mm}$ homogeneous steel against High Explosive Anti-Tank ammunition \\
She can't roll out the paste & It is able to roll out the enemies of the nation to the dust [38]. \\
\hline
\end{tabular}


It should be noted that gender stereotypes in this example are used not to create the opposition "man - woman" or "male - female", but "military civilian". Contrasting qualities and images of groups are brought into comparison, and the female stereotypes serve as a background on which an own ideal is constructed. Reproducing gender stereotypes this opposition accentuates gender asymmetry, which is based on the component good/bad that is of a value nature. Binarity as one of the basic principles of understanding gender differences is used to aggravate the disparities between social and professional groups. This is achieved through attributing female characteristics to an out-group and accusing it of inconsistency with the stereotype of masculinity. The validity of the conclusions is borne out by the following example, in which the opposition between a civilian woman and a military woman is mainstreamed. This example comprises two components, that are visual and verbal. The visual component represents two images: the first is a glamorous girl in front of expensive car; the second is a tank girl on a tank. The verbal component is a dialogue between two girls: "You see the way everyone keeps looking at me?" - "You really think so?" [38]. In this dialogue it is the visual component that shapes the main thrust: a girl in front of car serving as a background picture is associated with an idle lifestyle, corruption, frivolity and lustfulness, while a tanker girl personifies reliability, seriousness, strength, confidence, that are qualities traditionally attributed to men. This proves that at present gender stereotyping in the Armed Forces of Ukraine becomes flexible, and stereotypes are corrected depending on the social context, for example on the professional activity of the person and the object of stereotyping. Some of the reasons for this are linked with the military professional activity specific, which is that in the army efficiency in accomplishing the assigned tasks is possible only if there is a unified system of corporate goals, values and relations [35]. Gender identification in the Armed Forces of Ukraine turns out to be secondary, but identification with a military professional group becomes urgent. A woman in the Armed Forces of Ukraine, just like a man, becomes the supporter of the ideas and ideals of military professional activity, and the updated gender stereotype includes values and norms promoted by the corporate military culture, which we understand as an inherent in the military structure the system of basic values and ideas, socially significant formal and informal rules and norms of behavior, beliefs, customs and traditions [35] formed in the course of joint activities for the effective performance of combat missions. While not denying the importance of differences between the sexes for gender stereotyping and gender role formation in the Armed Forces of Ukraine, we nevertheless believe it is the corporate military culture that is becoming the springboard for changes in the female stereotypes and for the gradual smoothing of professional discrimination against women not only in the army, but throughout society. A woman in the corporate military culture is perceived, first of all, as a reliable comrade: "Lena, would you like to work in double harness?" - "Yes, of course!" - "OK, the uniform is in the closet, formation on the parade ground is at 8-00, don't be late!" [38]. This leads to the assumption that the inference about discrimination against women in the Armed Forces of Ukraine is premature. This is particularly so, when we recall that introducing the concept of gender equality in the Armed Forces of Ukraine has begun relatively recently. It takes time to become a professional soldier and work a way up from a cadet to a colonel, and it takes more time to reach the rank of general, and artificial acceleration of the integration of women into the Armed Forces of Ukraine, one of the indicators of which is the number of female senior officers and the number of leadership positions held in the army by women, can cause a serious undermining of the Ukrainian army combat capability.

\subsection{Constructive Function of Gender Stereotyping}

Effective implementation of combat mission is largely determined by the nature of the relationship between the members of the military units. The ability to understand the situation, to coordinate one's behavior in accordance with it, as well as in accordance with the behavior of other people, is a necessary condition for the existence of the military units. Formal (service) relationships in the military units comply strictly with the military statutes and regulations, which formulate the following basic principles: unity of command (authority delegated from only one individual), strict military discipline, subordination. The essence of the unity of command and strict subordination principles is dividing the military into rank groups that correlate with the command and control functions; imposing on superiors to exercise command functions and on subordinates to follow the orders with unquestioning obedience. Within the framework of formal (service) relationships, when personal sympathies and antipathies do not play a central role, female stereotypes in the Armed Forces of Ukraine have the potential to ensure consistency in the behavior of military men. The constructive function of gender stereotypes is activated under the impact of a specific military socio-psychological environment and is aimed at adoption the military men's beliefs and world view by every serviceman. The psychological category "adoption" is a multifaceted concept that has deep cultural, philosophical, religious and social roots. This can be illustrated by the following example: Duties of a military wife!!!! A girl is appointed to a post of wife from the most trained girls. She is responsible for maintaining internal order in the apartment, the preservation of property and funds available for the program aimed at promoting family wellbeing, alcohol (!) combat support. The wife unequivocally obeys her husband. She also has an obligation to withstand all the hardships and deprivation of family service..., well, life..., not to spare neither time nor effort in order to achieve family happiness. In the unit entrusted to her (family) she is responsible for food supply and timely provision of fuel (alcohol), lubricants (lard). For any 
violation of family status, she can be reprimanded and strict disciplinary measures should be taken at once in the form of extra guard duty in the kitchen. She must monitor the implementation of the daily routine; on the husband return she must stand at the position of attention and report on all incidents. Leaving the location of the apartment she must to inform the husband of time of her return to the place of permanent deployment, to know the number of personnel in the apartment, the purpose of their arrival and time of departure. Upon arrival of the mother-in-law she must immediately report to the husband, then monitor her actions in accordance with specific instructions received from the husband. After the command "lights out" she must be in bed in 40 seconds! And the most important duty is to live to see a time when her husband returns from the Joint Forces Operation! [38]. In this example, in order to have a better comprehending of the military service nature and to correlate the expression of his emotions and his behavior in accordance with it, as well as in accordance with other people's behavior, the individual turns to a simulation model that emphasizes female stereotypes typical of patriarchal culture. In this study a simulation model is considered as a set of parameters, criteria and restrictions (norms, standards), with which the behavior of an individual or a social group is assessed and predicted [1]. Elements of language game, some conventionality of this simulation model favor the emancipation of a serviceman, help to prevent the stress associated with the need to obey in armed forces, and also let adopt the form and manner of behavior in typical social situations that presuppose strict military discipline, subordination and unity of command. On the other hand, such simulation model that involves female stereotypes lets a serviceman perceive and evaluate a woman as a person of the opposite sex based on the characteristics of her inner world and her professional activities. This helps to overcome some barriers in communication, understand an another personality and establish harmonious relationships.

\subsection{Emotional-Evaluative Function of Gender Stereotyping in the Process of Interpersonal Interaction}

Next subject of interest from the perspective of the gender stereotype psychological functions, it is emotional nature of gender stereotypes, when gender identification is aimed at characteristics associated with the process of interpersonal interaction and not with socio-professional relations: One day this war will be over. And the girls will return from the front to love and give birth to children, they won't believe they have ever fired a weapon... The uniform will never conceal our military girl's ambrosial beauty. I am carrying in my hands an amulet for you. It will protect you from being hurt. I am carrying for you a human tenderness, which protects us in battles... [38]. In this case, stereotypes accentuate the feminine charm, softness, the need to nurture. The emotional-evaluative function of female stereotypes lets a military man of the Armed Forces of Ukraine to reproduce situations that are emotionally significant for him, in which his needs for recognition and love have been met. In the future, this can contribute to creation of psychological comfort and deep emotional ties between men and women in a military collective: I will follow a girl in camouflage to where the war is, and the sun will tell me the way. I will take a bullet for the girl in camouflage when shielding her from death... [38].

\subsection{Positive Effects of Female Stereotypes Functioning in the Ukrainian Military Corporate Culture}

Thus, discourse analysis confirms the results of a sociological study conducted by Dubchak [14], who denies the harmful influence of gender stereotypes on the process of integrating women into the Armed Forces of Ukraine. Moreover, we have noted the following positive effects of female stereotypes functioning in the Ukrainian military corporate culture: 1) destruction of gender typology, overcoming polarization between femininity and masculinity as polar opposite genders, creating relations between representatives of different genders that are based on trust and support; 2) changing the vector of gender priorities from the predominance of belonging to certain gender to the predominance of belonging to the corporate military culture; that makes it crucial to perceive and evaluate a woman, first of all, as a representative of military professional activity; 3 ) creation of psychological prerequisites for the prevalence of a positive emotional state in the military collective and formation of communication principles characterized by empathy.

\subsection{The Influence of the Cognitive-Adaptive Function of Stereotyping on the Female Military Personnel's Perception of Themselves}

In the second phase of this study we tried to answer the question, what really hinders the integration of women into the Armed Forces of Ukraine? We studied the influence of the female stereotypes on the female military personnel's perception of themselves and made the attempt to verify or disprove the Dubchak's hypothesis that the female psyche peculiarities, specifically the influence of gender stereotypes on the process of servicewoman self-identification, slow down the successful integration of women into the Armed Forces of Ukraine. From this perspective, it seems appropriate to analyze the Ukrainian "Military Service" group's posts regarding "Bereginya in uniform - 2020" competition (in Ukrainian culture Bereginya is the Goddess who protects people from disease and the evil forces) that was held among women military medical personnel: On the second day of the final selection stage 11 tender contestants presented to audiences a video presentation "My profession is a combat medic" on their way to this profession. After that the finalists demonstrated their creative abilities. They read poems, sang, danced, presented hand-embroidered paintings and icons...the major of medical service Victoria Palamarchuk (Dnipro) won the award for "Miss Professional Thoroughness", sergeant Lyubov Torchynovych (Lviv) won the award for "Miss Charm", sergeant Yaroslava Yurchuk 
(Mykolayiv) won the award for "Miss Audience Choice", second lieutenant of the Medical Service Corps Natalia Boyko (Kyiv) won the award for "Miss Creativity", sergeant Anastasia Samitska (Odessa) won the award for "Miss Grace”, staff sergeant Mariana Zhuk (Bila Tserkva) won the award for "Miss Photogenic", sergeant Lydia Kraevska (Kyiv) won the award for "Miss Beautiful Smile"... At the award ceremony the girls wore evening dresses and once again proved that they are not only highly professional medical personnel but also charming women who are able to impress with their beauty [38]. Analysis of the female military personnel's needs, abilities, beliefs, attitudes, values, which are reflected at the verbal level of the text presented above, proves that female military personnel identify themselves with a women who oriente towards the patriarchal stereotypes criteria. First of all, female military personnel position themselves as women with a set of characteristics traditionally assigned to the female gender. They demonstrate their orientation towards forming a family, and this fact is confirmed by highlighting attractive appearance and abilities, which are important in housekeeping and raising children. Professional skills among the presented award nominations take second place to other competing requirements. Thus, we concluded that the root of the predicament of integrating women into the Armed Forces of Ukraine is the psychological effect, which is caused by a negative impact of cognitive-adaptive function of stereotyping on the behavior of a woman who considers herself as one belonging to female stereotype [34].

\section{Conclusions}

Discourse analysis of female stereotype functions has proved that at the linguistic level the cognitive-adaptive function is realized in modern Ukrainian military noninstitutional discourse through the cognitive gender metaphor used by the military men. Feminine metaphors are becoming tools that breaks down traditional female stereotypes and offer a new perspective, namely the failure of polarization between the genders, as well as the trust and support of interaction between men and women in the military corporate culture. The value-protective function of female stereotypes is aimed to maintain collective values, justify and rationalize discriminatory attitudes towards the outgroups. Female stereotypes in the Armed Forces of Ukraine are used not to create the opposition "man - woman" or "male - female" but "military $\neg$ civilian". Constructive function of gender stereotyping favors the emancipation of a serviceman, helps to prevent the stress associated with the need to obey in armed forces, lets adopt the form and manner of behavior in typical social situations that presuppose strict military discipline, subordination and unity of command, lets a serviceman perceive and evaluate a woman based on the characteristics of her inner world and her professional activities. Emotional-evaluative function of female stereotypes helps a military man in the Armed Forces of Ukraine reproduce situations that are emotionally significant for him, in which his needs in recognition and love have been met. Further, this can contribute to creation of psychological comfort and deep emotional ties between men and women in a military collective. Discourse analysis of the female stereotype functions did not reveal the relationship of competition and hostility between femininity and masculinity in the Armed Forces of Ukraine. For today the female stereotyping in the Armed Forces of Ukraine is becoming flexible, and stereotypes are changing according to social context. The root cause of this process is the specifics of the military professional activities, when the efficiency in accomplishing the assigned tasks is possible only if there is a unified system for accepting corporate goals, values and relationships. Gender identification in the Armed Forces of Ukraine turns out to be secondary, but identification with a military professional group becomes urgent. A woman in the Armed Forces of Ukraine, just like a man, becomes the supporter of the ideas and ideals of military professional activity, and the updated female stereotype includes values and norms promoted by the corporate military culture. It is the corporate military culture that is becoming the springboard for changing in the female stereotypes and for the gradual smoothing of professional discrimination against women not only in the Armed Forces of Ukraine, but throughout Ukrainian society. So, in the Ukrainian military corporate culture, the influence of the female stereotypes on the perception of female military personnel by male military personnel have positive effects, which consist in: 1) destruction of gender typology, overcoming polarization between femininity and masculinity as polar opposite genders, creating relations between representatives of different genders that are based on trust and support; 2) changing the vector of gender priorities from the predominance of belonging to certain gender to the predominance of belonging to the corporate military culture; that makes it crucial to perceive and evaluate a woman, first of all, as a representative of military professional activity; 3) creation of psychological prerequisites for the prevalence of a positive emotional state in the military collective and formation of communication principles characterized by empathy. But we argue, that the main root of the predicament of integrating women into the Armed Forces of Ukraine is the psychological effect, which is caused by a negative impact of cognitive-adaptive function of stereotyping on the behavior, beliefs, attitudes, values of women who consider themselves as ones belonging to this stereotype.

\section{References}

[1] Afonin, E. A. (2014). Formation of the Armed Forces of Ukraine: social and socio-psychological problems. Kiev: Scientific and technical center "Psyche".

[2] Akhmadeeva, K. N. (2011). Constructing gender stereotypes in management: a thematic repertoire of discourse practices and strategies (Candidate Dissertation). Kazan: Bashkir State University. 
[3] Akhutina, T. V. (2008). Generation of speech. Neuro-linguistic syntax analysis. Moscow: publishing house of LKI.

[4] Andryushchenko, V. (1991). Cossacks and women. Science and society, 7, 55.

[5] Archer, E. M. (2013). The Power of Gendered Stereotypes in the US Marine Corps. Armed Forces \& Society, 39 (2), 359391. DOI: $10.1177 / 0095327 X 12446924$.

[6] Boldry, J., Wood, W., Kashy, D. (2001). Gender Stereotypes and the Evaluation of Men and Women in Military Training. Journal of Social Issues, 57, 689-705. DOI: 10.1111/00224537.00236.

[7] Borelli, E, Cacciari, C. (2019). The Comprehension of Metaphorical Descriptions Conveying Gender Stereotypes. An Exploratory Study. Front Psychol, 22 (10), 2615. DOI: 10.3389/fpsyg.2019.02615.

[8] Boyce, L. A., Herd, A. M. (2003). The Relationship Between Gender Role Stereotypes and Requisite Military Leadership Characteristics. Sex Roles 49, 365-378. DOI: 10.1023/A:1025164221364.

[9] Bragina, N. G. (2009). Mythology of stereotype and common knowledge. Stereotypes in language, communication and culture, 348-356.

[10] Collins-Dogrul, J., Ulrich J. R. (2018). Fighting Stereotypes: Public Discourse About Women in Combat. Armed Forces \& Society, 44 (3), 436-459. DOI: 10.1177/0095327X17715650.

[11] DeGroot, G. J. (2001) A few good women: Gender stereotypes, the military and peacekeeping. International $\begin{array}{lllll}\text { Peacekeeping, } & 8: & 23-38 . & \text { DOI: }\end{array}$ $10.1080 / 13533310108413893$.

[12] Doan, A., Portillo, S. (2019). Organizational Obliviousness Entrenched Resistance to Gender Integration in the Military. Publisher: Cambridge University Press. DOI: $10.1017 / 9781108665124$.

[13] Dontsov, A. I., Stefanenko, T. G. (2008). Social stereotypes: yesterday, today, tomorrow. Socialnaya psihologiya, 170-187.

[14] Dubchak, N. I. (2008). Women in the Armed Forces of Ukraine: Problems of Gender Policy. Strategic priorities, 4 (9), 187-192.

[15] Ervas, F. (2017). Another metaphor is possible. Challenging social stereotypes in figurative language comprehension. Reti, Saperi, Linguaggi, 4: 1, 79-96. DOI: 10.12832/87357.

[16] Gritsenko, E. S. (2011). Metaphor and gender in categorization and conceptualization processes. Cognitive linguistics issues, 2, 13-17.

[17] Jorgensen, M., \& Phillips, L. (2002). Discourse analysis as theory and method. London: Sage Publications.

[18] Kabalevskaya, A. I. (2012). Ideas about gender stereotypes in modern social psychology. Psychological research, 2 (22), 4.

[19] Kalagin, Yu. A. (2014). Stereotypes of female servicemen about the army and military service. HRANI, 2 (106), 112117.

[20] Kalmikov, H. (2016). Discursive practices as components of professional speech activity of psychologists. Psycholinguistics, 20 (1), 98-111.
[21] Karpyuk, G. (2018). "If a woman joined the army, she must take on responsibilities," said an officer of the General Staff of the Armed Forces of Ukraine. «OBOZREVATEL». URL: https://www.mil.gov.ua/diyalnist/genderni-pitannya-u-sferibezpeki/yakshho-zhinka-prijshla-do-armii-to-povinnaprijnyati-i-obovyazki-oficzer-gsh-zsu.html.

[22] Kirk, I. (1987). Images of Amazons: Marriage and Matriarchy. Images of Women in Peace and War, 27-39.

[23] Koenig, A. M., Eagly, A. H. (2014). Evidence for the social role theory of stereotype content: observations of groups' roles shape stereotypes. J. Pers. Soc. Psychol. 107, 371-392. DOI: $10.1037 / \mathrm{a} 0037215$.

[24] Kozulya, O. (1993). Women in the history of Ukraine. Kiev: Scientific Opinion.

[25] Krotikov, V. P. (2012). Features of gender processes in the Armed Forces of Ukraine. Bulletin of the National University of Defense of Ukraine, 6 (31), 317-322.

[26] Marcenyuk, T., Gricenko, A., Kvit, A., Berlinskaya, M. (2018). Integration of Women into the Armed Forces: Prospects and Problems of Ukrainian Society. Laboratorium, 10 (2), 13-33. DOI: 10.25285/2078-1938-2018-10-2-13-33.

[27] Miller, L. L., Moskos, C. (1995). 'Humanitarians or Warriors? Race, Gender and Combat Status in Operation Restore Hope. Armed Forces and Society, 21 (4), 625-31.

[28] Order of the Cabinet of Ministers of Ukraine of October 28, 2020 № 1544-r National Action Plan for the implementation of UN Security Council Resolution 1325 "Women, Peace, Security" for the period up to 2025. URL: https://zakon.rada.gov.ua/laws/show/1544-2020$\%$ D $1 \% 80 \#$ Text.

[29] Rezanova, Z. I. (2011). Gender metaphor: typology, lexicographic interpretation, contextual representation. Tomsk State University Bulletin, 2 (14), 47-57.

[30] Rollins, A. (2012). Act like a lady! Reconsidering gender stereotypes and the exclusion of women from combat in the light of challenges to "don't ask, don't tell." Southern Illinois University of Law Journal, 36, 355-365.

[31] Situational and Personal Determination of Discourse / Ed. N. D. Pavlova, I. A. Zachesova (2007). Moscow: Publishing house "Institute of Psychology of Russian Academy of Sciences".

[32] Slipushko, G. (2019). The features of gender stereotypes of the personality of military woman in the conditions of Antiterrorist Operation, Joint Forces Operation. Psychological journal, 5 (3), 153-167. DOI: 10.31108/1.2019.3.23.10.

[33] Sowell, T. (2004). Affirmative Action Around the World: An Empirical Study. Yale University Press.

[34] Steele, C. M., Aronson, J. (1995). Stereotype threat and the intellectual test performance of African Americans. Journal of Personality and Social Psychology, 69 (5), 797-811.

[35] Vedernikov, A. A., Shulakov, A. V. (2019). Understanding the essence of the concept «Corporate culture of an officer» by cadets of National Guard of Russia institute as a component of the professional tasks effectiveness. Professional education in the modern world, 9 (4), 3276-3283. DOI: 10.15372/PEMW20190414. 
[36] Vykhor, S., Toporenko, O. (2016). Ways of integration of women into the Armed Forces of Ukraine: pedagogical aspect. Topical issues of the humanities: an intercollegiate collection of researchers working with young people with Drohobych workers at Ivan Franko University, 16, 282-204.
[37] Yavornytsky, D. I. (1990). History of the Zaporozhian Cossacks. Kiev: Scientific Opinion.

[38] «Military service». FB (Facebook). Retrieved from https://www.facebook.com/groups/326775474408976. 